\title{
Subminimal Inhibitory Concentrations of the Disinfectant Benzalkonium Chloride Select for a Tolerant Subpopulation of Escherichia coli with Inheritable Characteristics
}

\author{
Birgitte Moen $^{1,2, *}$, Knut Rudi ${ }^{1,2,3}$, Erlend Bore ${ }^{1,4}$ and Solveig Langsrud ${ }^{1}$
}

1 Nofima-Norwegian Institute of Food, Fisheries and AquacultureResearch,Osloveien 1, N-1430 Ås, Norway; E-Mails: knut.rudi@umb.no (K.R.); erlend.bore@ gilde.no (E.B.); solveig.langsrud@nofima.no (S.L.)

2 Department of Chemistry, Biotechnology and Food Science, Norwegian University of Life Sciences,P.O. Box 5003, N-1432 Ås, Norway

3 Hedmark University College, Holsetgata 22, 2306 Hamar, Norway

4 Nortura SA, P.O.Box 40, 4064 Stavanger, Norway

* Author to whom correspondence should be addressed; E-Mail: birgitte.moen@ nofima.no; Tel.: +47-64-97-01-00; Fax: +47-64-97-03-33.

Received: 1 December 2011; in revised form: 20 January 2012 / Accepted: 19 March 2012 / Published: 28 March 2012

\begin{abstract}
Exposure of Escherichia coli to a subminimal inhibitory concentration (25\% below MIC) of benzalkonium chloride (BC), an antimicrobial membrane-active agent commonly used in medical and food-processing environments, resulted in cell death and changes in cell morphology (filamentation). A small subpopulation (1-5\% of the initial population) survived and regained similar morphology and growth rate as non-exposed cells. This subpopulation maintained tolerance to BC after serial transfers in medium without $\mathrm{BC}$. To withstand $\mathrm{BC}$ during regrowth the cells up regulated a drug efflux associated gene (the $a c r B$ gene, member of the AcrAB-TolC efflux system) and changed expression of outer membrane porin genes $(o m p F W)$ and several genes involved in protecting the cell from the osmotic- and oxidative stress. Cells pre-exposed to osmotic- and oxidative stress (sodium chloride, salicylic acid and methyl viologen) showed higher tolerance to BC. A control and two selected isolates showing increased BC-tolerance after regrowth in BC was genome sequenced. No common point mutations were found in the $\mathrm{BC}$ - isolates but one point mutation in gene $\operatorname{rps} A$ (Ribosomal protein $\mathrm{S} 1$ ) was observed in one of the isolates. The observed tolerance can therefore not solely be explained by the observed
\end{abstract}


point mutation. The results indicate that there are several different mechanisms responsible for the regrowth of a tolerant subpopulation in $\mathrm{BC}$, both $\mathrm{BC}$-specific and general stress responses, and that sub-MIC of $\mathrm{BC}$ may select for phenotypic variants in a sensitive E. coli culture.

Keywords: Escherichia coli; quaternary ammonium compounds; benzalkonium chloride; selection of subpopulation; efflux pump; osmotic and oxidative stress response

\section{Introduction}

Quaternary ammonium compounds (QACs), such as benzalkonium chloride (BC), are used in a wide range of applications such as disinfectants in food-processing and medical environments and as preservatives in pharmaceuticals and cosmetics. These antimicrobials are membrane-active agents with a target site predominantly at the cytoplasmic (inner) membrane and are also believed to damage the outer membrane of gram negative bacteria, thereby promoting their own uptake (for an overview, see [1,2]). The widespread use of these agents can lead to resistant bacteria, which may limit efficacy in pharmaceutical and cosmetic products or disinfection effects in food and medical applications [3]. There is also the concern that resistance to disinfectants contributes to antibiotic resistance [4-6], which may limit treatment options for microbial infections. There are several reports on bacteria adapted to high levels of $\mathrm{BC}$ and cross-resistance to other antimicrobial agents [7-10]. The involvement of efflux pumps $[8,11,12]$ and reduction in the outer membrane porin OmpF $[11,13]$ have been suggested as possible resistance mechanisms. In addition, changes in the LPS layer [13,14], changes in fatty acid profiles [15,16] and changes in cell surface hydrophobicity $[8,17]$ have been suggested to influence acquisition of resistance in gram negative bacteria. Previous research reports have mainly focused on strains adapted to high concentrations of BC after serial transfer in gradually higher concentrations of $\mathrm{BC}$.

In a previous study [9], we showed that after one transfer of E. coli in a BC-concentration $75 \%$ below MIC, the cells survived in higher concentrations in a bactericidal test. In the first transfer in the adaptation study, the MIC of BC doubled. Also, exposure of E. coli to salicylate, chenodeoycholate and methyl viologen increased the MIC of BC, indicating a role of general stress response systems. The mechanisms behind these responses were not determined, but in a later study, we found that E. coli cells exposed to BC-concentrations allowing growth had a remarkably different response from that of a range of other stress conditions [18]. While other stress factors (heat, cold, acid, alkali, salt, glycerol, ethanol and ethidium bromide) resulted in increased lag time and/or reduced growth rate, exposure to $\mathrm{BC}$ resulted in an initial killing of cells followed by growth at similar rates as non-stressed cells. Also, despite the major impact of BC on survival, the number of genes involved during regrowth was remarkably low compared to other stress factors. Only three genes (b1171, osmB and ykfE (ivy)) were identified as showing significantly different levels of expression (up regulated) for cells growing in the presence of BC. Gene $b 1171$ has no known function, osmB encodes a lipoprotein and $y k f E$ (ivy) encodes an inhibitor of C-lycozyme [19,20]. As far as we know, there are no publications on the mechanisms involved in the survival strategy of $E$ coli exposed to subminimal inhibitory concentrations 
(sub-MICs) of BC and the following growth in the presence of BC. There are two recent studies of the effect of sub inhibitory concentrations of BC in Pseudomonas [21,22], one was over time in biofilm and the other was a long-term continuous culture subjected to increasing levels of BC, suggesting that sub-inhibitory concentrations of $\mathrm{BC}$ are sufficient to select for adapted variants.

The aim of the current work was to investigate the survival mechanisms of E. coli growing in BC. This was done by microarray analysis (two new replicate microarray experiments performed and combined with previously published data for analysis), live-dead fluorescence microscopy, quantitative real-time PCR, knock-out strain analyses, as well as traditional growth studies. In addition, a control and two isolates selected after growth in BC were genome sequenced using the 454 (Roche) sequencing platform.

We present results showing that exposure to $\mathrm{BC}$ (25\% below MIC) selects for a tolerant subpopulation of E. coli employing both $\mathrm{BC}$ specific and general stress responses, and that this subpopulation appears to have inheritable characteristics.

\section{Results and Discussion}

\subsection{Morphological Changes and Cultivability as Analyzed by CFU after BC Exposure}

The original MIC of BC in TSB is about $12 \mu \mathrm{g} / \mathrm{mL}$ [18]. Growth of E. coli in the presence of a BC-concentration below MIC $(9 \mu \mathrm{g} / \mathrm{mL})$ was analyzed by plate counts and optical density (Figure 1A), and morphological changes visualized by BacLight live/dead fluorescence microscopy (Figure 1B). The addition of $\mathrm{BC}$ resulted in $\sim 50 \%$ reduction of $\mathrm{CFU} / \mathrm{mL}$ in the first $60 \mathrm{~min}$ and a total of $\sim 98 \%$ reduction after $180 \mathrm{~min}$. Exposure to $\mathrm{BC}$ also affected the morphology of the cells (filamentation). As also found in a previous study [18], the cells multiplied at a rate similar to the control after $\sim 300 \mathrm{~min}$ and the cells regained their original morphology after 360-420 min.

To exclude the possibility that regrowth after the initial kill was due to neutralization of $\mathrm{BC}$, bacteria grown in BC to mid-exponential growth phase were re-inoculated in fresh medium with BC. The regrowth times of these cells were reduced by approx. $220 \mathrm{~min}$ compared to cells pre-grown in medium without BC (and similar to what was observed for stationary phase control cells inoculated in TSB without BC). This indicated that the observed growth was not a result of neutralization of antibacterial action, but that the population of cells surviving exposure to $\mathrm{BC}$ differed from the original culture and showed higher tolerance. Regrowth of cells after the initial killing phase was delayed (compared to direct re-inoculation from BC) if the cells were grown for 1-4 transfers in medium without $\mathrm{BC}$, but still shorter (approx. $150 \mathrm{~min}$ ) than for control cells (approx. $280 \mathrm{~min}$ ) inoculated in $\mathrm{BC}$. 
Figure 1. (A) Growth curves (CFU/mL and OD) and (B) BacLight pictures of E. coli cells exposed to BC (9 $\mu \mathrm{g} / \mathrm{mL})$ and control at 0 (stationary phase), 60, 120, 180, 240, 300, 360 and $420 \mathrm{~min}$ after inoculation. Open symbols represent the control, closed symbols represent cultures with $\mathrm{BC}$. The arrows and numbers 1,2, 3 and 4 refer to the sampling points used for real-time PCR experiments.
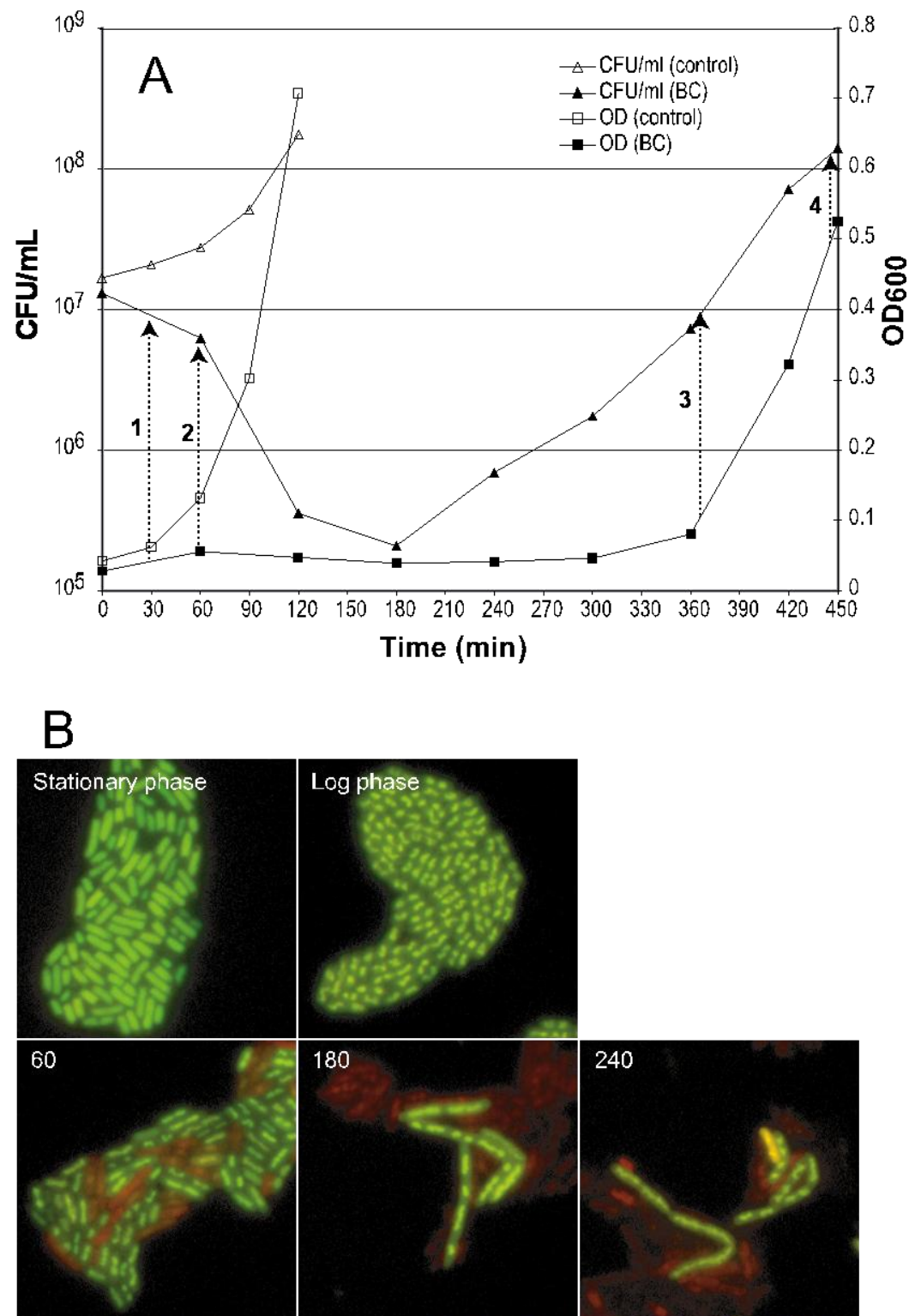

\section{0}
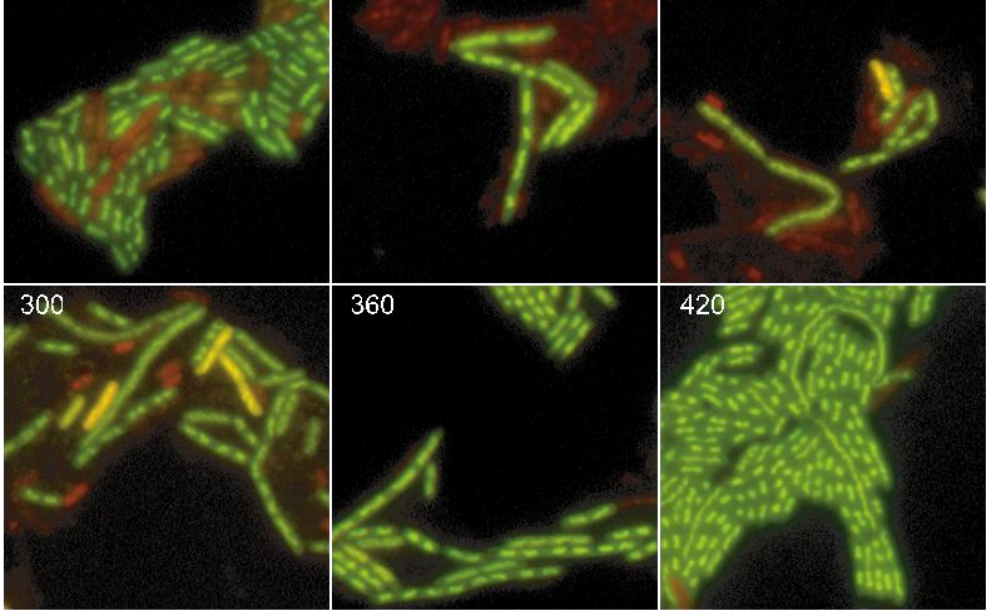

\subsection{Microarray Analyses}

Samples for microarray analyses were collected when the cells had regained exponential growth at a cell density of approx. $1 \times 10^{8} \mathrm{CFU} / \mathrm{mL}$ (time point 4 in Figure 1). The data presented represents data 
from two new microarray hybridizations, BC $9 \mu \mathrm{g} / \mathrm{mL}$ versus control (no BC) (see experimental Section 3.8) in addition to a previously published experiment where only three genes $($ b1171, osmB and $y k f E$ (ivy)) were identified as significantly different (up regulated) in cells grown in the presence of BC (7 $\mu \mathrm{g} / \mathrm{mL}$ and $\mathrm{BC} 9 \mu \mathrm{g} / \mathrm{mL})$ [18]. These combined data were used to identify 41 genes showing significantly different levels of expression (FDR < 0.05) in BC $(9 \mu \mathrm{g} / \mathrm{mL})$ compared to the control (Table 1). Among these genes were the $a c r B$ efflux gene, the $o m p F$ and $o m p W$ outer membrane protein genes and several genes involved in osmotic- and/or oxidative stress, in addition to several genes with unknown function. Some of these genes were studied further by knock-out mutations and real-time PCR (see Section 2.4). Among those with unknown function was gene $y k f E$. This gene has previously been shown to be a strong inhibitor of C-type lysozyme and was correspondingly renamed ivy [19,20]. In addition to its enzymatic activity on the bacterial cell, lysozyme also possesses a non-enzymatic inactivation mechanism. The most likely mechanism for microbial activity of lysozyme is membrane disruption as observed for several other antimicrobial peptides, rather than enzymatic degradation of the bacterial murein layer [23]. It is therefore possible that gene $y \mathrm{kfE}$ may have a function in protecting the cell against cell damaging agents.

Table 1. Genes significantly different (FDR < 0.05) in BC $(9 \mu \mathrm{g} / \mathrm{mL})$ compared to the control (based on two new microarray experiments and data from a previous experiments [18]) and corresponding $t$-values, expression (log 2 compared to the control) and description.

\begin{tabular}{|c|c|c|}
\hline $\begin{array}{l}\text { Function and } \\
\text { Gene Name }\end{array}$ & $\begin{array}{c}\log 2 \\
(\mathrm{BC} / \mathrm{Control})\end{array}$ & Gene Description and References \\
\hline \multicolumn{3}{|l|}{ Efflux System } \\
\hline $\operatorname{acr} B$ & 0.9 & $\begin{array}{l}\text { AcrAB-TolC efflux pump }[24,25] \text {. The } a c r B \text { gene has previously been linked to BC } \\
\text { resistance }[8,12] \text {. }\end{array}$ \\
\hline \multicolumn{3}{|c|}{ Osmotic and/or Oxidative Stress } \\
\hline hdeA & 1.6 & $\begin{array}{l}\text { The hdeA gene encodes the acid stress chaperone HdeA that enhances survival in } \\
\text { extreme acid conditions [26]. The hdeA gene has also been shown to be induced by } \\
\text { sodium salicylate [27]. }\end{array}$ \\
\hline$h \operatorname{tr} A(\operatorname{deg} P)$ & 0.8 & $\begin{array}{l}\text { Membrane-associated serine endoprotease (known heat shock protein that has also } \\
\text { been shown to be induced by ampicillin and kanamycin in E. coli [28] and are } \\
\text { hypothesized to participate in the degradation of oxidatively-damaged proteins } \\
\text { localized in the cell envelope }[29,30] \text {. }\end{array}$ \\
\hline ompF & -1.7 & $\begin{array}{l}\text { The OmpC and OmpF porins account for approx. } 2 \% \text { of the total protein content of the } \\
\text { cell [31] and allow for the passive diffusion of solutes across the outer membrane. } \\
\text { ompF has previously been shown to be regulated by changes in osmolarity [32] and in } \\
\text { response to oxidative stress [27] and has been linked to BC resistance [13]. }\end{array}$ \\
\hline osmB & 1.6 & $\begin{array}{l}\text { osmB is a multistress-responsive gene and encodes an outer membrane lipoprotein of } \\
\text { unknown function [33]. osmB is transcribed under the control of two independent } \\
\text { promoters, one is responsible for the response to the growth phase and to osmotic } \\
\text { shock, whereas the other is the target of response regulator RcsB [34] which is a } \\
\text { positive regulatory gene for capsule (colanic acid) synthesis. }\end{array}$ \\
\hline
\end{tabular}


Table 1. Cont.

\begin{tabular}{|c|c|c|}
\hline $\begin{array}{c}\text { Function and } \\
\text { Gene Name }\end{array}$ & $\begin{array}{c}\log 2 \\
(\mathrm{BC} / \mathrm{Control}) \\
\end{array}$ & Gene Description and References \\
\hline \multicolumn{3}{|c|}{ Osmotic and/or Oxidative Stress } \\
\hline pflB & 1.1 & $\begin{array}{l}\text { Pyruvate formate lyase I. Gene } p f l B \text { has previously been shown to be induced by } \\
\text { sodium salicylate [27]. }\end{array}$ \\
\hline $\operatorname{rpos}$ & 0.8 & $\begin{array}{l}\text { The } \operatorname{rpoS} \text { gene }\left(\sigma^{\mathrm{S}}\right) \text { acts as the master regulator of stationary phase response and } \\
\text { general stress response [35] and controls the expression of genes involved in (among } \\
\text { others) osmotic- and oxidative stress [36]. }\end{array}$ \\
\hline$y c i D($ ompW) & 2.2 & $\begin{array}{l}\text { Gene } y \text { ciD (or ompW) encodes an outer membrane protein (OMP) and mutants that } \\
\text { lacked the OmpW protein have been shown to be resistant to colicin } \mathrm{S} 4 \text { [37]. Studies } \\
\text { on Vibrio alginolyticus [38] have shown the up regulation of an OmpW homolog in } \\
\text { response to high osmolarity }(\mathrm{NaCl} \text { ) and it was hypothesized that OmpW might act as } \\
\text { OmpC of E. coli in response to salinity stress. }\end{array}$ \\
\hline$y b d Q(u s p G)$ & 1.1 & $\begin{array}{l}\text { The } y b d Q \text { (or } u s p G \text { ) gene share homologies with UspA and have been shown to } \\
\text { accumulate under various growth inhibitory conditions and induced by heat shock and } \\
\text { may function as a universal stress protein [39]. Gene } y b d Q \text { has previously been shown } \\
\text { to be up regulated in response to osmotic upshift in E. coli [40]. }\end{array}$ \\
\hline$y f i D$ & 2.0 & $\begin{array}{l}\text { Glycine radical cofactor that can reactivate pyruvate formate lyase after oxidative } \\
\text { stress. Gene } y f i D \text { has been shown to be up regulated during oxidative stress and was } \\
\text { hypothesized to function in protecting bacterial cells from oxidative stress }[41,42] \text {. }\end{array}$ \\
\hline \multicolumn{3}{|l|}{ Other } \\
\hline$b 2097(f b a B)$ & 1.0 & Fructose 1,6-bisphosphate aldolase \\
\hline edd & -2.1 & Phosphogluconate dehydratase \\
\hline eutH & -0.9 & Putative integral membrane protein \\
\hline$f r u B$ & 1.0 & Fructosephosphotransferase enzyme III \\
\hline gntK & -3.3 & $\begin{array}{l}\text { Genes gntKTU constitute the GntI system and metabolize gluconate via the } \\
\text { Entner-Doudroff pathway [43]. gntT and gnt } U \text {, encodes a high- and low- affinity } \\
\text { gluconate transporters, respectively, and gntK, encode a } \\
\text { thermo-resistant gluconokinase. }\end{array}$ \\
\hline gnt $T$ & -3.1 & \\
\hline$g n t U_{-} l$ & -3.1 & \\
\hline$h d h A$ & 0.6 & 7-alpha-hydroxysteroid dehydrogenase \\
\hline $\operatorname{lrh} A$ & -1.0 & $\begin{array}{l}\text { Gene } l h r A \text { encodes a LysR-type regulator LrhA [44] a new transcriptional key } \\
\text { regulator of flagella, motility and chemotaxis genes in E. coli. LrhA is also shown to } \\
\text { function as a regulatory component in the RpoS-dependent growth phase repression } \\
\text { of } o m p F[45] \text {. }\end{array}$ \\
\hline malZ & 0.7 & Maltodextrin glucosidase \\
\hline$n a g E$ & -0.6 & $N$-acetylglucosamine-specific enzyme II of phosphotransferase system \\
\hline $\operatorname{nirD}$ & 3.5 & Nitrite reductase $[\mathrm{NAD}(\mathrm{P}) \mathrm{H}]$ subunit \\
\hline$p l s B$ & 0.7 & Glycerolphosphate acyltransferase activity \\
\hline$r b s B$ & 1.5 & D-ribose binding protein, periplasmic \\
\hline $\operatorname{rplN}$ & -0.4 & 50S ribosomal subunit protein L14 \\
\hline speB & -0.6 & Agmatinase \\
\hline$t k t A$ & 0.4 & Transketolase; binds Zn(II) \\
\hline tors & -0.7 & Sensor kinase for torCAD operon \\
\hline
\end{tabular}


Table 1. Cont.

\begin{tabular}{|c|c|c|}
\hline $\begin{array}{c}\text { Function and } \\
\text { Gene Name }\end{array}$ & $\begin{array}{c}\log 2 \\
\text { (BC/Control) }\end{array}$ & Gene Description and References \\
\hline \multicolumn{3}{|l|}{ Other } \\
\hline tpiA & 0.8 & Triosephosphate isomerase \\
\hline$y b b U(a l l R)$ & 0.7 & Repressor for allantoin (all) and glyoxylate ( $\mathrm{gcl})$ utilization operons \\
\hline$y e c I(f t n B)$ & 1.2 & Ferritin-like protein, function unknown \\
\hline$y h i W(\operatorname{gad} W)$ & 1.7 & Positive AraC-type regulator of gadA and gadBC \\
\hline$y i h G$ & 0.6 & Characterized as poly(A) polymerase II, but this claim has been contradicted \\
\hline$y k f E(i v y)$ & 1.4 & $\begin{array}{l}\text { The } y k f E \text { gene has previously been shown to be a strong inhibitor of } \\
\text { C-type lysozyme and was correspondingly renamed ivy }[19,20] \text {. }\end{array}$ \\
\hline \multicolumn{3}{|l|}{ Unknown } \\
\hline b1171 & 2.1 & $\begin{array}{l}\text { Gene } b 1171 \text { (or } y m g D \text { ) has no known function and produced no hit on a Pubmed } \\
\text { search. The protein sequence produced no close hits other than a } 100 \% \text { identity to a } \\
\text { hypothetical protein in Shigella flexneri (BLAST). }\end{array}$ \\
\hline$b 2107$ & 1.0 & Function unknown \\
\hline$b 2295$ & 0.5 & Function unknown \\
\hline yaiL & 0.8 & Function unknown \\
\hline$y b j X$ & 0.6 & $\begin{array}{l}\text { Gene } y b j X \text { has no known function but has } 99 \% \text { protein homology to a putative } \\
\text { enzyme in Shigella flexneri } 2 \text { a and } 55 \% \text { protein homology to a putative VirK } \\
\text { protein in Salmonella enterica ( } 180 \text { identical of } 330 \text { amino acids) (BLAST). }\end{array}$ \\
\hline yieE & 1.0 & Function unknown \\
\hline yieF & 0.8 & $\begin{array}{l}\text { The yieE gene has no known function but showed } 97 \% \text { identity ( } 246 \text { identical of } \\
253 \text { amino acids) to a hypothetical protein from Shigella flexneri and } 77 \% \text { identity } \\
\text { (194 identical of } 253 \text { amino acids) to a putative cytoplasmic protein from } \\
\text { Salmonella typhimurium (BLAST). }\end{array}$ \\
\hline
\end{tabular}

Gene description is derived from the cited references and from EcoGene [46].

\subsection{Susceptibility of Knock-out Mutants}

Based on difference in expression during regrowth in BC (Table 1) and availability, the role of selected genes was further investigated using single gene knock-out mutants and an expression strain. These were tested by MIC tests and regrowth tests. Regrowth time reflects the initial kill by BC and is defined as the time from inoculation to the time where the cells had reached their initial start concentration, as measured by increasing CFU and/or OD (although it cannot be excluded that a subpopulation is growing at an earlier stage). For calculation see Section 3.1. Only two (ompC and $y b j X)$ of the 12 knock-out strains and one expression strain investigated (Table 2) showed altered regrowth time compared to the wild type when exposed to $\mathrm{BC}$. Knock-out strain $y b j X$ had a slight increase in regrowth time compared to the control (+ 120-150 min) and was therefore studied further in a growth competition study. The $\operatorname{ompC}$ strain had a faster regrowth $(176.0 \pm 22.2 \mathrm{~min})$ compared to the wild type strain $(254.7 \pm 2.4 \mathrm{~min})$ when $\log$ phase cells were used as inoculum. A delayed regrowth was also observed for knock-out strain $b 1171$ but this was not reproducible. These observations are discussed further under Section 2.4. The MIC of BC was similar for the knock-out strains and the wild type strain. Knock-out strains $b 1171$ and $y b j X$ were studied further by real-time PCR and in a direct growth competition with the wild type by use of real-time PCR analysis (see Section 2.4). 
Table 2. Knock-out strains and expression strain used in this study.

\begin{tabular}{|c|c|c|}
\hline Strain & Knock-Out Strain Details ${ }^{\text {a }}$ & Source or Reference \\
\hline MG1655 & b1171::Tn5KAN-I-SceI & University of Wisconsin, Madison $^{\mathrm{b}}$ \\
\hline MG1655 & gntK::Tn5KAN-I-SceI & University of Wisconsin, Madison ${ }^{b}$ \\
\hline MG1655 & gntT::Tn5KAN-I-SceI & University of Wisconsin, Madison ${ }^{b}$ \\
\hline MG1655 & hdeA::Tn5KAN-I-SceI & University of Wisconsin, Madison ${ }^{b}$ \\
\hline MG1655 & $\operatorname{lrh} A:: \operatorname{Tn} 5 \mathrm{KAN}-2$ & University of Wisconsin, Madison ${ }^{b}$ \\
\hline MG1655 & omp $C:$ Tn5KAN & [47] \\
\hline MG1655 & ompF::Tn5KAN & {$[47]$} \\
\hline MG1655 & osmB::Tn5KAN-2 & University of Wisconsin, Madison ${ }^{b}$ \\
\hline MG1655 & $y b j X:: \operatorname{Tn} 5 \mathrm{KAN}-\mathrm{I}-\mathrm{Sce} \mathrm{I}$ & University of Wisconsin, Madison ${ }^{b}$ \\
\hline MG1655 & yciD::Tn5KAN-I-SceI & University of Wisconsin, Madison ${ }^{b}$ \\
\hline MG1655 & yieF::Tn5KAN-I-SceI & University of Wisconsin, Madison ${ }^{b}$ \\
\hline MG1655 & $i v y:$ KAN & [19] \\
\hline MG1655 & $\begin{array}{l}\text { pAA410-arabinose-inducible Ivy } \\
\text { overexpression strain }\end{array}$ & [19] \\
\hline
\end{tabular}

${ }^{\mathrm{a}}$ KAN, kanamycin resistance; ${ }^{\mathrm{b}}$ E. coli Genome project [48]. Published by Deckers et al., 2004 [19].

\subsection{Real-Time PCR Analyses}

Based on microarray- and knock-out strain results genes $a c r B, b 1171, o m p F$ and $y b j X$ were studied further by real-time PCR experiments. Time points equivalent to sampling points $1-4$ in Figure 1 were investigated. The early time points were chosen to investigate if the genes with altered expression during mid-logarithmic growth also were involved in the early response to BC. However, it cannot be excluded that the expression measured during these early time points could be a mixture of initial BC response and the transition from stationary growth phase to exponential growth phase. The cells grown in the presence of BC $(9 \mu \mathrm{g} / \mathrm{mL})$ were compared to non-stressed cells (see Section 3.5). The analyses showed that the investigated genes were also involved in the early response to BC. The expression of $a c r B$ in $\mathrm{BC}$ exposed cells was higher during the early time points than during the regrowth phase, with a maximum expression $(3.6 \pm 0.2)$ ( $\log 2$ of fold change) $60 \mathrm{~min}$ after exposure. The expression stabilized to approx. 1.0 during the growth phase (Figure 2). A similar expression profile was observed for gene $y b j X$ with maximum expression at $60 \mathrm{~min}(2.9 \pm 0.5)$ but this gene did not seem to be up regulated during the growth phase. Gene $b 1171$ was up regulated at all time points during BC exposure with the highest expression at $60 \mathrm{~min}$ (3.3). The expression of ompF declined after $\mathrm{BC}$ exposure and was lowest at $60 \mathrm{~min}(-3.1 \pm 0.5)$ and appeared to stabilize at approx. -1.6 during the growth phase.

The results from the real-time PCR analyses from mid-exponential growth phase (time point 4 (Figure 1), OD 0.5) were also compared to previous microarray results (OD 0.5) [18]. The results showed that the real-time PCR results coincided well with the previous microarray results for genes $a c r B$ and $o m p F$. Gene $b 1171$ had a higher expression in the real-time PCR analyses, while gene $y b j X$ had a lower expression. Both reference genes $a c c D$ and gapA were used and gave similar results. 
Figure 2. Real-time PCR results of Escherichia coli cells exposed to BC at 30 and $60 \mathrm{~min}$, and at OD 0.1 and 0.5 after inoculation (equivalent to sampling points 1, 2, 3 and 4, respectively, shown in Figure 1). The expression is presented as $\log 2$ of fold change compared to the reference gene, $a c c D$, and the control. The expression was based on 3 biological replicates.

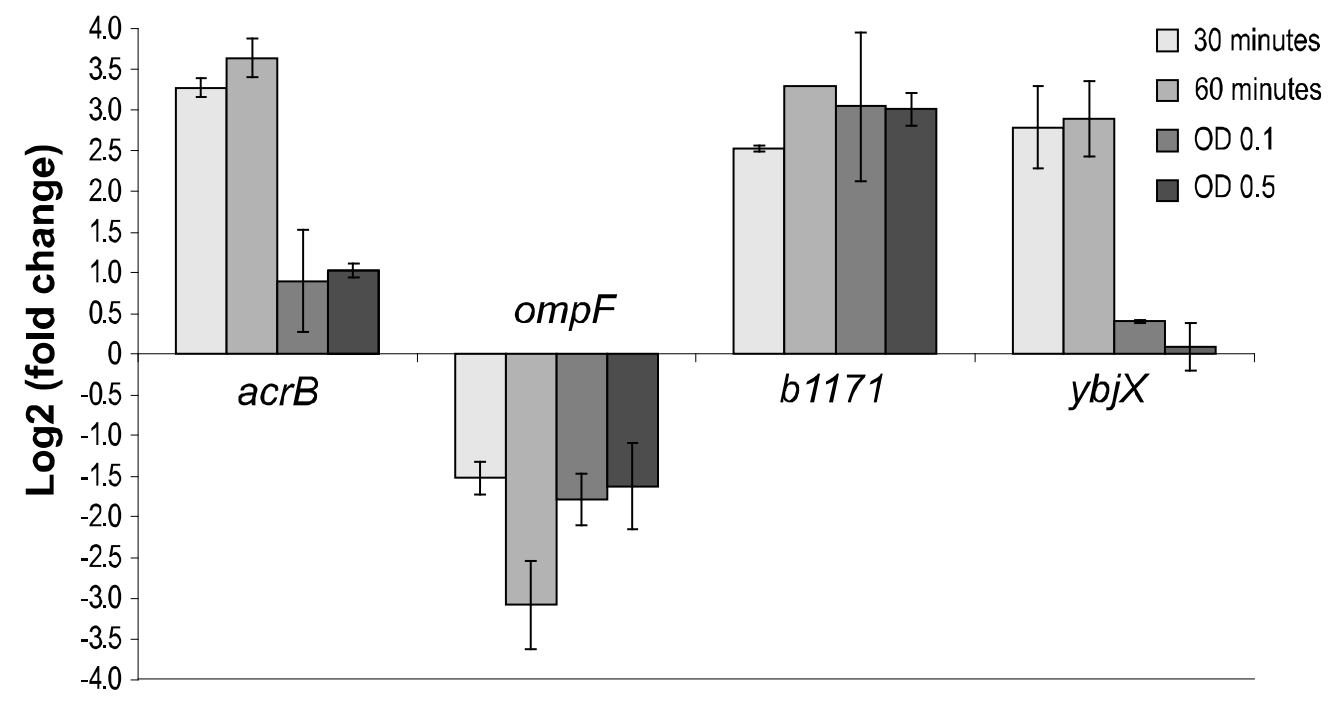

Figure 3. Real-time PCR results from a competitive growth experiment of mixed cultures of knock-out strain b1171 and the wild type, and knock-out strain $y b j X$ and the wild type. The time points used were equivalent to sampling points 1, 2, 3 and 4 shown in Figure 1. The $\log 2$ of fold change was calculated using the $\Delta \Delta \mathrm{CT}$ calculation based on gene $a c c D$ and the kanamycin resistance gene related to the growth in the presence and absence of BC. The expression was based on 3 biological replicates.

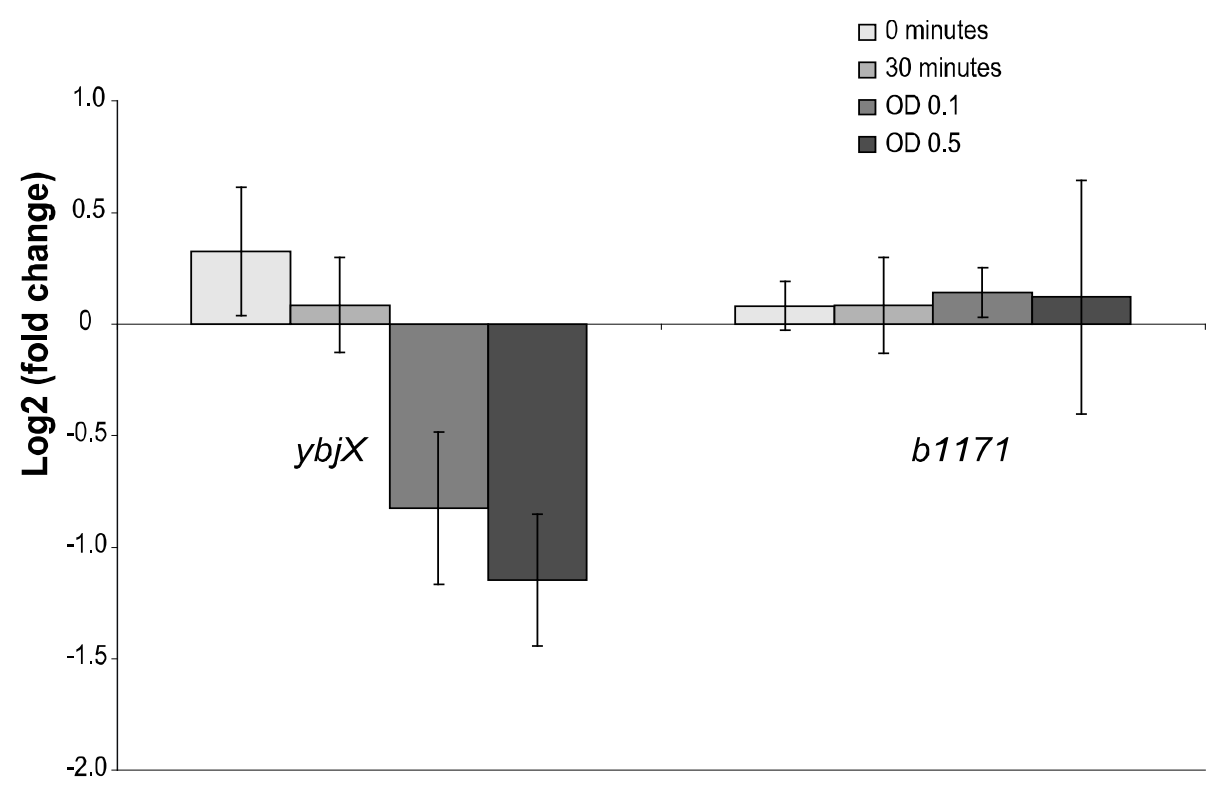

Based on the results from the knock-out mutant regrowth tests in BC and the above real-time PCR results, direct growth competition tests with the wild type were performed for knock-out strains $b 1171$ and $y b j X$. The direct growth competition ( $\log 2$ of expression between the reference gene $(a c c D)$ and 
the kanamycin resistance gene (related to growth in the presence and absence of BC), showed that the $y$ bjX knock-out strain had a slower growth compared to the wild type when exposed to BC (Figure 3). The growth of the $b 1171$ knock-out strain in BC was not significantly different from the wild type.

The gene expression analysis showed that during regrowth in $\mathrm{BC}$, the cells had a higher expression of the $a c r B$ gene involved in the AcrAB-TolC efflux system [25] than the control cells. The acrB gene has previously been linked to BC resistance [8,12] and encodes an RND (resistance nodulation cell division)-type transporter, AcrB, that together with a periplasmic accessory protein AcrA and the TolC outer membrane channel composes the AcrAB-TolC multidrug efflux system in E. coli. The AcrAB efflux system removes antibiotics, and other lipophilic and amphiphilic inhibitors, from the cytoplasm, through the periplasm, directly to the external media [24,25,49]. The acrB gene was not up regulated during growth in any of the other stress conditions [18] and we therefore believe that AcrAB-TolC contribute to survival in BC by removing BC from the cytoplasm.

Gene $y$ bjX was highly expressed at 30 and $60 \mathrm{~min}$ after exposure to $\mathrm{BC}$ and knock-out analyses (direct competition growth) showed that the $y b j X$ knock-out strain had impaired survival compared to the wild type when exposed to BC. This gene has no known function in E. coli, but showed protein homology to somA (S.t.) and virK (S.f.) Salmonella entericia. The virK gene has previously been shown to confer resistance to the cationic peptide polymyxin B, probably by contributing to remodeling of the bacterial outer membrane [50]. It is therefore possible that gene $y b j X$ has a similar role of remodeling the bacterial cell envelope in response to $\mathrm{BC}$ in $E$. coli.

Several of the genes that showed changed expression (microarray results) during growth in BC ( $h d e A, h t r A(\operatorname{deg} P), o m p F, o m p W, o s m B, p f l B, r p o S, y b d Q$ (uspG) and yfiD) (see Table 1 and Figure 2) have previously been associated to osmotic- and oxidative stress. This coincides with the results from our previous study where $E$. coli cells pre-cultivated in the presence of the oxidative agent salicylate resulted in higher MIC of $\mathrm{BC}$ [9]. The ompF gene was down regulated in response to $\mathrm{BC}$ and has previously been linked to $\mathrm{BC}$ resistance as well as osmotic- and oxidative stress [13,27,51]. The ompW (yciD) gene was up regulated and it has been hypothesized that OmpW might act as OmpC of E. coli in response to salinity stress [38]. OmpF and OmpC are major constituents of the outer membrane and are involved in osmoregulation of the cell. At low osmolarity, OmpF predominates, while at high osmolarity OmpC replaces the OmpF due to the larger pore and faster flow rate in OmpF compared to OmpC [52]. It is also known that the permeability to antimicrobial agents through the outer membrane in E. coli greatly depends on the contents of $\mathrm{OmpF}$ and $\mathrm{OmpC}$ porin proteins, and that OmpF deficiency makes cells resistant to some antibiotics [53-55]. Low concentrations of QACs have previously been shown to damage the outer membrane and result in the loss of many of its osmoregulatory functions $[2,56]$. The fact that the $o m p F$ knock-out strain did not show an increase in $\mathrm{BC}$ tolerance indicates that the observed down regulation of $o m p F$ was a response to increased osmolarity and not a result of preventing BC entering the cytoplasm through OmpF (as is the case for ampicillin [47,57]). This hypothesis was strengthened by the fact that the ompC knock-out strain (log phase) had an increased tolerance to $\mathrm{BC}$, theoretically resulting in decreased expression of omp $F$ as a response to increased osmolarity in addition to absence of OmpC [52]. 


\subsection{Osmotic- and Oxidative Stress}

In a previous study [9], we showed that exposure to compounds such as salicylate and methyl viologen resulted in increased MIC of BC but no molecular studies were performed. The genetic response obtained in the present study support that common mechanisms are involved in protection against $\mathrm{BC}$ and osmotic or oxidative stress. To confirm previous findings and test the association with osmotic stress, growth in $\mathrm{BC}$ for cells pre-grown in the presence of $0.5 \mathrm{M}$ and $0.77 \mathrm{M}(4.5 \%)$ sodium chloride $(\mathrm{NaCl}): 5 \mathrm{mM}$ and $10 \mathrm{mM}$ salicylic acid (SAL) and $0.1 \mathrm{mM}$ and $0.2 \mathrm{mM}$ methyl viologen (MV) was tested. For all three compounds, the regrowth time in $\mathrm{BC}$ was reduced compared to cells pre-grown in pure TSB (Figure 4).

Figure 4. Regrowth time in $\mathrm{BC}$ (min) for cells pre-grown in osmotic and oxidative stress; $\mathrm{NaCl}$ (sodium chloride), SAL (salicylic acid), MV (methyl viologen). $0 \mathrm{M}$ is the non pre-exposed control.

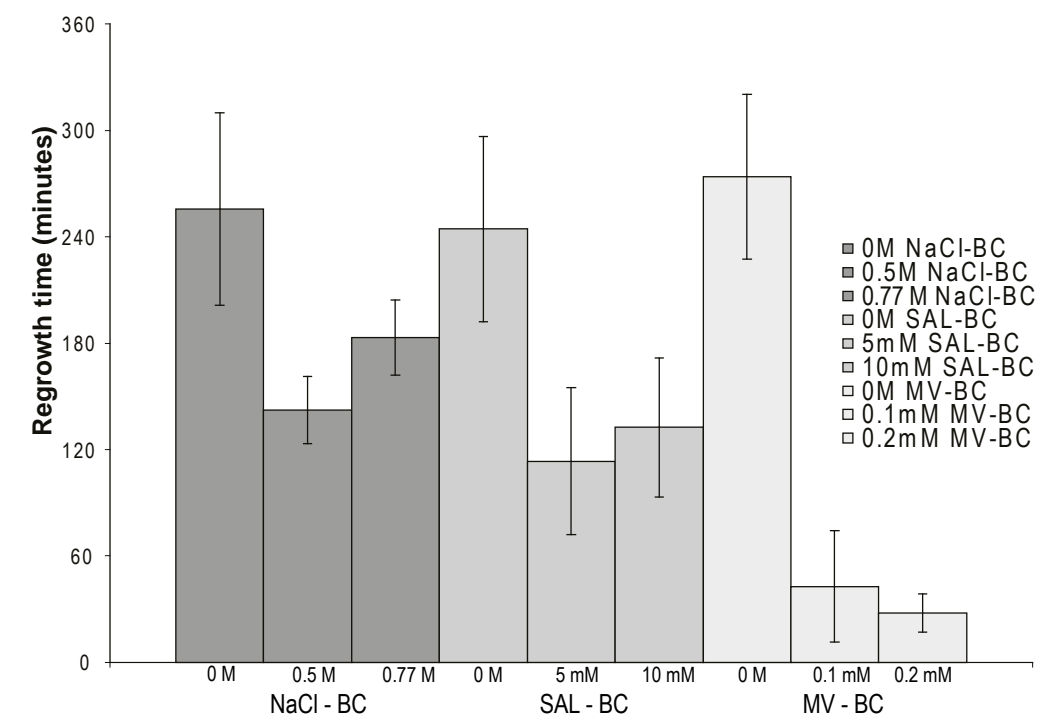

\subsection{Characteristics of BC Isolates}

To investigate if the surviving subpopulation after BC exposure was a homogeneous population, a screening of 94 colonies selected after regrowth in $\mathrm{BC}$ were screened in Bioscreen for BC tolerance (see Section 3.11). The results showed that approx. $10 \%$ of the isolates grew better in $\mathrm{BC}$ than the non pre-exposed control while the remaining colonies has similar growth as the control. This indicated that the subpopulation consisted of a heterogeneous group. The two isolates with the fastest regrowth in BC compared to the control (M95 and M100) were studied further for growth in BC (see Figure 5) and selected for genome sequencing to look for common mutations. The two isolates had smaller colony morphology on TSA but had similar growth in TSB as the control. At $15 \mu \mathrm{g} / \mathrm{mL}$ BC the reduction in time of regrowth compared to the control was -306 and -236.7 min for M95 and M100, respectively. The isolates were also tested for maintenance of tolerance after ten repetitive overnight inoculations in medium without BC (more than 100 generations). The isolates maintained their tolerance to BC. Two random small colony variants from the control were also tested. These did not show any increased 
tolerance to $\mathrm{BC}$, indicating that the small colony morphology itself was not responsible for increased $\mathrm{BC}$ tolerance.

Figure 5. Growth curves (OD-log scale) of the Control (circle symbols), M95 (square symbols) and M100 (triangle symbols) in Bioscreen exposed to BC $(0,11,12,13,14$ and $15 \mu \mathrm{g} / \mathrm{mL}$ ). The vertical bars represent the standard deviation of the ten replicates (10 wells per sample and concentration).
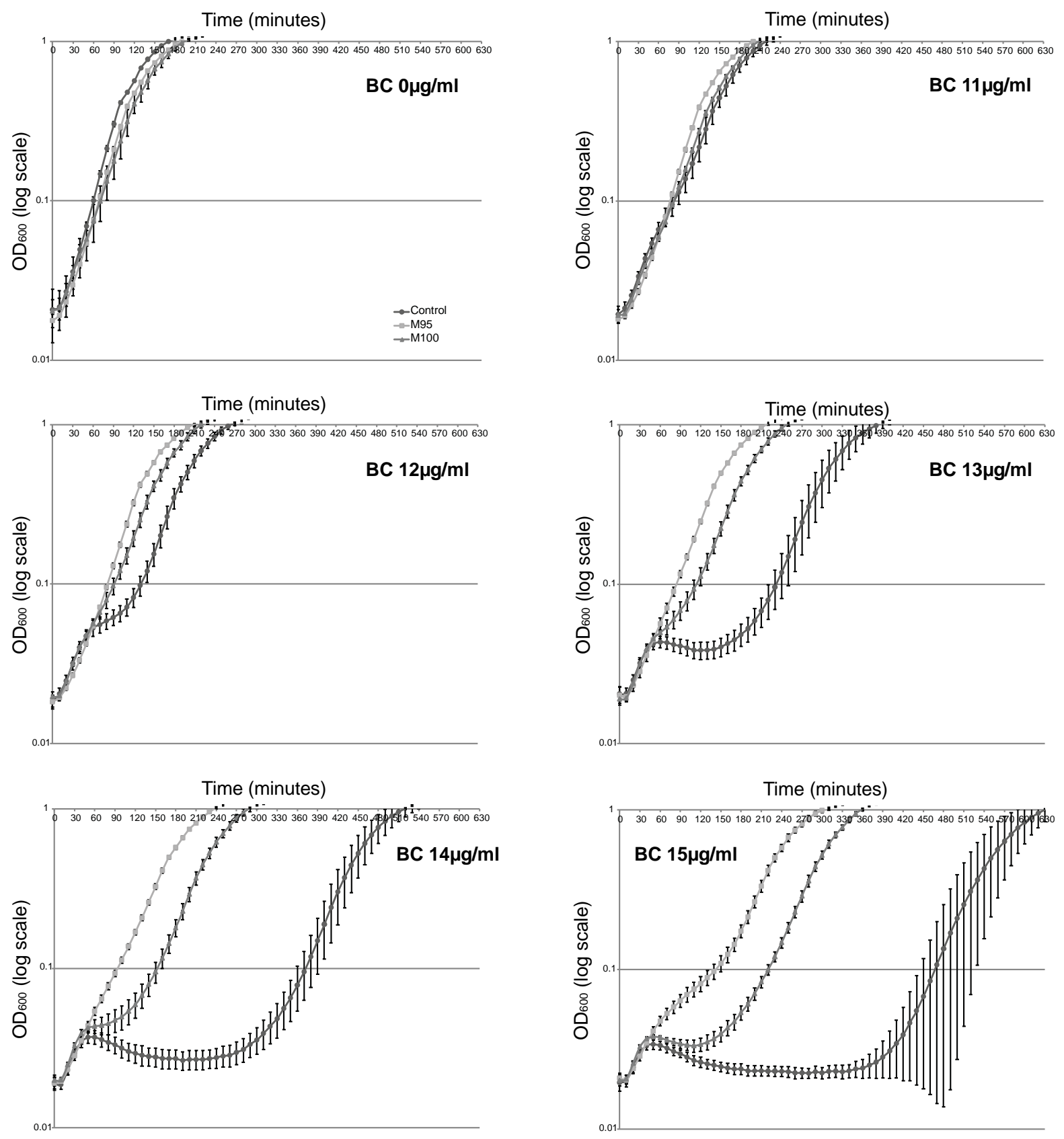

Genome sequencing: Genome sequencing of the control and the two BC selected isolates (M95 and M100) revealed three single point mutations (in the control, M95 and M100), compared to the reference genome ( $E$. coli U00096), leading to an amino acid substitution, in genes $k d p D, h c p$ and one single point mutation in a non-coding region. A single point mutation in gene $\operatorname{rps} A$ (nucleotide position 
795 in the rpsA gene; $\mathrm{T} \rightarrow \mathrm{G}$ ) leading to an amino acid substitution (Asp-265 $\rightarrow \mathrm{Glu}$ ) was found exclusively in one of the BC exposed isolates (M95) (15x coverage) (see Table 3 ).

Table 3. Single point mutations identified in the Control, M95 and M100 when assembled with the E. coli U00096 reference genome.

\begin{tabular}{|c|c|c|c|c|c|c|}
\hline \multirow{2}{*}{ Allele Variation } & \multicolumn{3}{|c|}{ Single Point Mutations (+/-) } & \multirow{2}{*}{$\begin{array}{c}\text { Reference } \\
\text { Position }\end{array}$} & \multirow{2}{*}{ Gene Annotations } & \multirow{2}{*}{$\begin{array}{l}\text { Amino Acid } \\
\text { Substitution }\end{array}$} \\
\hline & Control & M95 & M100 & & & \\
\hline $\mathrm{G} \rightarrow \mathrm{T}$ & + & $+{ }^{a}$ & $+{ }^{a}$ & 720994 & Gene: $k d p D$ & $\mathrm{Gln} \rightarrow \mathrm{Lys}$ \\
\hline $\mathrm{A} \rightarrow \mathrm{G}$ & $+{ }^{a}$ & + & + & 911614 & Gene: $h c p$ & Leu $\rightarrow$ Pro \\
\hline $\mathrm{C} \rightarrow \mathrm{T}$ & + & $+{ }^{a}$ & + & 3957957 & No coding region & - \\
\hline $\mathrm{T} \rightarrow \mathrm{G}$ & $-{ }^{\mathrm{b}}$ & + & $-{ }^{\mathrm{b}}$ & 962012 & Gene: $r p s A$ & $\mathrm{Asp} \rightarrow \mathrm{Glu}$ \\
\hline
\end{tabular}

${ }^{a}$ The single point mutations were not reported when using default parameters, but were verified by visual inspection (the lowest coverage was seven); ${ }^{b}$ Visual inspection confirmed the absence of the single point mutation in the Control and M100. This was also verified by sequencing.

Ribosomal protein S1, the product of the essential $r p s A$ gene, consists of six imperfect repeats of the same motif. The mutation was not in the S1 RNA binding domain. The total coverage was 13.5 for the Control, 11.6 for M95 and 12.3 for M100 given an average read length of $374.4 \mathrm{bp}$. The mutation was verified by PCR and sequencing part of the rpsA gene (position 683-988) in the control, M95 and M100. In addition, part of the rpsA gene in ten other isolates (seven that grew faster than the control and three that grew slower) selected after growth in BC was sequenced. None of these had any mutation. The RpsA protein is a target site for antimicrobial agents in the tetracycline class [58] as well as other antibacterial agents that inhibit the elongation process during bacterial protein synthesis $[59,60]$. The fact that the point mutation was observed in only one of the BC selected isolates, several isolates still had a higher tolerance to $\mathrm{BC}$ and showed altered phenotypic characteristics compared to the control, indicates that there are other additional mechanisms responsible for the observed tolerance to $\mathrm{BC}$.

Based on the survival rate, the characteristics of isolates selected after $\mathrm{BC}$ exposure and the genome sequencing of a control and two BC exposed isolates, it is likely that BC concentrations below MIC (25\% below MIC) select for phenotypic variants in a sensitive culture with the ability to survive and grow in BC. Comparable studies in Pseudomonas, although using a longer exposure period, have suggested that concentrations of BC below MIC are sufficient to select for adapted variants in sensitive cultures. Sub-inhibitory concentrations of BC (increasing at two-generation intervals) were shown to select for spontaneous variants of Pseudomonas aeruginosa grown in long-term (792 h) continuous culture [22] and adaptation over time (24 h and $96 \mathrm{~h}$ biofilm) of Pseudomonas fluorescens in biofilms to low levels of BC (10 $\mu \mathrm{g} / \mathrm{mL}-50 \%$ below MIC) has been suggested by Dynes et al. (2009) [21]. This study shows that even short exposure to concentrations of $\mathrm{BC}$ allowing growth can select for $\mathrm{BC}$ tolerant variants of $E$. coli. The genome sequenced isolates maintained their tolerance to $\mathrm{BC}$ for more than 100 generations and re-inoculation study of the whole sub-population showed that the cells maintained some level of tolerance even after repetitive passages in medium without BC (approx. 13 generations). This maintenance of tolerance cannot solely be explained by the initial biomolecular- and/or gene expression stress response and appeared to be dependent on the initial 
selection of a subpopulation. Nor did the genome sequence of the $\mathrm{BC}$ isolates reveal any common mutation explaining the inheritable $\mathrm{BC}$ tolerance.

\section{Experimental Section}

\subsection{Strains and Growth Conditions}

The Escherichia coli strain used in this study was the genome-sequenced strain K12 MG1655 [61]. Bacteria were grown on tryptone soya agar (TSA, Oxoid) overnight at $37{ }^{\circ} \mathrm{C}$. Cultures were prepared by inoculating one colony from TSA to $5 \mathrm{~mL}$ tryptone soya broth (TSB, Oxoid), incubation overnight at $37{ }^{\circ} \mathrm{C}$, shaking at $200 \mathrm{rpm}$. This culture was initially diluted 1:10 and used to inoculate TSB with or without BC (dilutions from 50\% BC stock solution, Norwegian pharmaceutical depot) (40-50 mL total volume) to a final concentration of approx. $1 \times 10^{7} \mathrm{CFU} / \mathrm{mL}$ (1:100 dilution of overnight culture). The $\mathrm{BC}$ concentrations used in all experiments was $9 \mu \mathrm{g} / \mathrm{mL}$ ( $25 \%$ below MIC), except in the selection of isolates for genome sequencing, where the concentration was higher, $11.5 \mu \mathrm{g} / \mathrm{mL}$, due to a new batch of BC (the stock solution used has a concentration of approximately $50 \%$ (that is $5 \times 10^{5} \mu \mathrm{g} / \mathrm{mL}$ ) according to the manufacturer). The regrowth time was nevertheless the same as for previous experiments using $9 \mu \mathrm{g} / \mathrm{mL}$ BC. In the Bioscreen experiments testing the two isolates chosen for genome sequencing, the $\mathrm{BC}$ concentrations were $11-15 \mu \mathrm{g} / \mathrm{mL}$ due to the new $\mathrm{BC}$ batch and the fact that the cells were less susceptible to $\mathrm{BC}$ during growth in Bioscreen plates (probably due to the smaller volume and difference in shaking regime). The lowest concentration of $\mathrm{BC}$ totally preventing growth after $24 \mathrm{~h}$ (the minimal inhibitory concentration) in TSB was $12 \mu \mathrm{g} / \mathrm{mL}$, as also shown previously [18], using approx. $1 \times 10^{7} \mathrm{CFU} / \mathrm{mL}(1: 100$ dilution of overnight culture) as inoculum. The knock-out strains (containing a kanamycin resistance selection gene) (Table 2), were grown overnight at $37{ }^{\circ} \mathrm{C}$ on TSA containing $50 \mu \mathrm{g} / \mathrm{mL}$ kanamycin (Sigma). The arabinose-inducible expression strain (ivy) (Table 2) was grown overnight at $37{ }^{\circ} \mathrm{C}$ on TSA containing $100 \mu \mathrm{g} / \mathrm{mL}$ ampicillin (Sigma) and $50 \mu \mathrm{g} / \mathrm{mL}$ kanamycin. Induction of $i v y$ was performed by adding $0.2 \%(\mathrm{w} / \mathrm{v}) \mathrm{L}-(+)$-arabinose (Sigma) at an optic density $\left(\mathrm{OD}_{600}\right)$ of approx. 0.2. The cells were then grown to an $\mathrm{OD}$ of approx. 0.5 before $5 \mathrm{~mL}$ of this culture was used to inoculate $45 \mathrm{~mL}$ TSB containing $\mathrm{BC}$ and $0.2 \%(\mathrm{w} / \mathrm{v})$ arabinose. Growth experiments were performed with and without arabinose induction. The wild type was used as the control and grown under similar conditions as the expression strain.

The regrowth time reflects the initial killing and was defined as the time from inoculation to the time where the cells had reached their initial start concentration as measured by CFU and/or OD and estimated to be the time point where the linear regression line ( $\mathrm{Y}=\mathrm{aX}+\mathrm{b}$ ) equaled the optical density $\left(\mathrm{OD}_{600}\right)$ at time zero $(\mathrm{OD}$ at time zero $=\mathrm{aX}+\mathrm{b})$. The linear regression line was based on three points in the linear area of the OD curve.

\subsection{BacLight Live-Dead Fluorescence Microscopy}

A $1 \mathrm{~mL}$ bacterial culture was centrifuged at $10,000 \mathrm{~g}$ at $4{ }^{\circ} \mathrm{C}$ in a micro centrifuge for seven min. The supernatant was removed and the cells resuspended in $1 \mathrm{~mL}$ of filter sterilized peptone water. This suspension was diluted to give approximately $1 \times 10^{7} \mathrm{CFU} / \mathrm{mL}$, and $0.5 \mathrm{~mL}$ of this dilution mixed with $0.5 \mathrm{~mL}$ of the BacLight (Molecular Probes) mixture (BacLight ampoules mixed in $5 \mathrm{~mL}$ of filter 
sterilized water). The BacLight/cell mixture was incubated for $15 \mathrm{~min}$ in the dark at $4{ }^{\circ} \mathrm{C}$ before being filtered down on a 0.22 micron, black polycarbonate filter (Osmonics Inc.). The filter was washed twice with $1 \mathrm{~mL}$ filter sterilized peptone water and then viewed by fluorescence microscopy (Leica DMLB microscope) using a RT color spot camera (Mode 2.2.0; Diagnostic Instruments, Inc.: Burroughs, Mich., USA) [62] and Spot Advanced software (version 3.0; Meyer Instruments: Houston, Tex., USA) [63].

\subsection{RNA Extraction}

Total RNA was extracted using the RNeasy Protect Bacteria Mini Prep kit (Qiagen) as recommended by the manufacturer including the "on-column" DNase treatment. The concentration and purity of the total RNA was analyzed using NanoDrop ND-1000 spectrophotometer (NanoDrop Technologies, Inc.).

\subsection{Reverse Transcription}

Total RNA was reverse transcribed by using random primers. Reaction mixture $(20 \mu \mathrm{L})$ contained $300 \mathrm{ng}$ of total RNA, $100 \mathrm{ng}$ random primers (Invitrogen) and $1 \mu \mathrm{L} 10 \mathrm{mM}$ dNTP mix in a reaction volume of $13 \mu \mathrm{L}$ was denatured at $65{ }^{\circ} \mathrm{C}$ for $5 \mathrm{~min}$, snap cooled on ice and centrifuged briefly. The reaction mix was left at room temperature for $10 \mathrm{~min}$ to allow the random primers to anneal to the template. Then $4 \mu \mathrm{L} 5 \times$ First Strand buffer (Invitrogen), $2 \mu \mathrm{L} 0.1$ M DTT was added and the reaction mix was incubated at $42^{\circ} \mathrm{C}$ for two min before $1 \mu \mathrm{L}(200 \mathrm{U} / \mu \mathrm{L})$ SuperScript II reverse transcriptase (Invitrogen) was added. The labeling reaction was incubated at $42{ }^{\circ} \mathrm{C}$ for $50 \mathrm{~min}$. The reaction mix was centrifuged briefly and incubated at $70{ }^{\circ} \mathrm{C}$ for $15 \mathrm{~min}$ before centrifuged briefly again. Two reverse transcriptase reactions were made for each biological replicate of RNA in addition to one negative control (without enzyme). After the reverse transcriptase reaction, the cDNA was added, $20 \mu \mathrm{L}$ water, and $2 \mu \mathrm{L}$ of this was used as template in the quantitative real-time PCR analyses.

\subsection{Quantitative Real-time PCR}

The expression of genes $a c r B, b 1171, o m p F$ and $y b j X$ were analyzed at 4 different time points (Figure 1) after inoculation in medium with and without BC $(9 \mu \mathrm{g} / \mathrm{mL}) ; 30$ and $60 \mathrm{~min}$ and at an $\mathrm{OD}_{600}$ of approximately 0.1 and 0.5 . Different time points for the $\Delta \mathrm{C}_{\mathrm{T} \text { (control) }}$ (see data analysis) were used to calculate the $\Delta \mathrm{C}_{\mathrm{T}(\mathrm{BC})}$ at the 4 different time points. For time points 30 and $60 \mathrm{~min}$, the values from the control sample at time 0 was used while the values from the control sample at OD 0.1 and OD 0.5 were used for the corresponding optical densities for cells grown in the presence of BC. The selection of the reference genes $(a c c D$ and $g a p A)$ was based on the previous microarray experiment on various stress conditions [18] with the criteria that these genes did not change significantly compared to the control during the 11 stress conditions tested. In the time course experiments only gene $a c c D$ was used as a reference gene, since the gapA reference gene was not an optimal choice when measuring expression during both the non-growth and growth phases.

Primers and TaqMan ${ }^{\circledR}$ probes (MGB) (Table 4) were designed using Primer Express software ABI PRISM $^{\circledR}$ software (version 1.0; Applied Biosystems: Foster city, CA, USA) [64]. The probe contained FAM (6-carboxyfluorescein) as fluorescent reporter dye covalently linked to the 5'end, and a 
non-fluorescent quencher (NFQ) was covalently linked close to the 3 ' end. The reporter signal was normalized to the emission of an internal reference dye (ROX-6-carboxy-X-rhodamine).

Table 4. Primers and fluorogenic probes for real-time PCR analyses.

\begin{tabular}{|c|c|c|c|}
\hline Gene & Probe or Primers & Sequence (5'-3') & Denaturation Temp. $\left({ }^{\circ} \mathrm{C}\right)$ \\
\hline \multirow{3}{*}{$a c c D$} & probe & CGCAGTGAATTCC & 70 \\
\hline & forward primer & TGCCGCCTGGATTCCA & 59 \\
\hline & reverse primer & GTCGATCGCGCCTTTCTC & 58 \\
\hline \multirow{3}{*}{ gapA } & probe & CGAAACTGCTCGTAAAC & 69 \\
\hline & forward primer & AAGCAACTGGTCTGTTCCTGACT & 58 \\
\hline & reverse primer & TTCGCACCAGCGGTGAT & 58 \\
\hline \multirow{3}{*}{$a c r B$} & probe & TGCGATGGTTTTCG & 69 \\
\hline & forward primer & GCGCTTTCTCGCAAATCAA & 59 \\
\hline & reverse primer & CGATTGCGGGCAGGTTAA & 59 \\
\hline \multirow{3}{*}{$y b j X$} & probe & CATCGCCGTAGTTTT & 68 \\
\hline & forward primer & TCGGCCGGGTAAATTCTG & 58 \\
\hline & reverse primer & CGAGCGCAGCAAAAATTTCT & 59 \\
\hline \multirow{3}{*}{ b1171_ymgD } & probe & CCCGCAAATGC & 68 \\
\hline & forward primer & ACTGAATCAGGTTTGCGCTAAAG & 59 \\
\hline & reverse primer & TCATCAATTGCCGTGATCAAC & 58 \\
\hline \multirow{3}{*}{ отрF } & probe & ACCTGGGTAAAAACGA & 68 \\
\hline & forward primer & TGGCCTGAACTTCGCTGTT & 58 \\
\hline & reverse primer & GAACGGCGTGCAGTGTCA & 59 \\
\hline \multirow{3}{*}{ KAN } & probe & TGCGCCGGTTGC & 69 \\
\hline & forward primer & TTGATGCGCTGGCAGTGT & 58 \\
\hline & reverse primer & GGACAATTACAAACAGGAATCGAA & 58 \\
\hline
\end{tabular}

All probes were MGB probes (5' label: 6FAM and 3' label: MGBNFQ (Minor groove binder/Non-fluorescent quencher).

Amplification reaction mixture $(25 \mu \mathrm{L})$ contained $2 \mu \mathrm{L}$ template (cDNA) or 20 ng DNA; 1× TaqMan buffer A; $5 \mathrm{mM} \mathrm{MgCl}_{2}, 200 \mu \mathrm{M}$ each of dATP, dCTP, dGTP and dUTP; $80 \mu \mathrm{M}$ AmpErase uracil $N$-glycosylase; $0.2 \mu \mathrm{M}$ forward/reverse primer; $0.1 \mu \mathrm{M}$ MGB probe; $1.25 \mathrm{U}$ AmpliTaq Gold DNA polymerase (Applied Biosystems). Before amplification, the reaction mixture was heated to $50{ }^{\circ} \mathrm{C}$ for two min and then denatured at $95{ }^{\circ} \mathrm{C}$ for $10 \mathrm{~min}$. The amplification profile was as follows: 40 cycles of $95{ }^{\circ} \mathrm{C}$ for $15 \mathrm{~s}$ and then $60{ }^{\circ} \mathrm{C}$ for one min. Reactions were performed in the Abi Prism 7900HT Sequence Detection System (Applied Biosystems). Reaction conditions were programmed and data were analyzed using the SDS software (version 2.2; Applied Biosystems: Foster City, CA, USA, 2003).

\subsection{DNA Extraction}

DNA was extracted using the DNeasy Tissue Kit (Qiagen). Briefly, 100-1000 $\mu$ L bacteria was centrifuged at $5000 \mathrm{~g}$ for $10 \mathrm{~min}$ at $4{ }^{\circ} \mathrm{C}$. The supernatant was discarded and the pellet was frozen at $-20{ }^{\circ} \mathrm{C}$ for later DNA purification. The manufacture protocol was followed from this point. The concentration and purity of the DNA was analyzed using NanoDrop ND-1000 spectrophotometer 
(NanoDrop Technologies, Inc.) and 20 ng of DNA was used as template in the quantitative real-time PCR analyses.

\subsection{Knock-out Strain Analyses}

Knock-out strains and the expression strain were tested for altered regrowth time compared to the wild type after exposure to $\mathrm{BC}$ (and absence of $\mathrm{BC}$ ). A diluted overnight culture (as described in strains and conditions) was used as inoculum in all experiments. In addition, the $о т р C$ and $о т р F$ knock-out strains were inoculated with $\log$ phase cells $\left(\mathrm{OD}_{600}\right.$ approx. $\left.0.5\left(1 \times 10^{8} \mathrm{CFU} / \mathrm{mL}\right)\right)$. Two of the knock-out strains ( $b 1171$ and $y b j X)$ were also selected for competitive growth with the wild type strain in the presence and absence of BC using quantitative real-time PCR (see Section 3.5). The wild type and the selected knock-out strains were combined in equal amounts (mixed culture) and samples were collected for purification of DNA at time zero (before addition of BC), at $30 \mathrm{~min}$ after exposure and at the optical density $\left(\mathrm{OD}_{600}\right)$ of approx. 0.1 and 0.5 . The two first time points were selected to capture the initial stress response to $\mathrm{BC}$ while the next two time points were selected to analyze initial growth (approx. $1 \times 10^{7} \mathrm{CFU} / \mathrm{mL}$ ) and mid-exponential growth (approx. $1 \times 10^{8} \mathrm{CFU} / \mathrm{mL}$ ), respectively. The method was based on the change in a reference gene, $a c c D$, versus the kanamycin resistance gene (KAN) inserted into the knock-out strains using the $\Delta \Delta \mathrm{C}_{\mathrm{T}}$ calculation (User Bulletin \#2: ABI PRISM 7700 Sequence Detection System). In this calculation $\Delta \Delta \mathrm{C}_{\mathrm{T}}=\left[\Delta \mathrm{C}_{\mathrm{T}(\mathrm{BC})}-\Delta \mathrm{C}_{\mathrm{T}(\mathrm{Control})}\right]$, where $\Delta \mathrm{C}_{\mathrm{T}}=\mathrm{C}_{\mathrm{T}(\mathrm{KAN})}-\mathrm{C}_{\mathrm{T}(a c c D)}(\mathrm{BC}=$ presence of $\mathrm{BC}$ and Control $=$ absence of $\mathrm{BC})$.

\subsection{Data Analysis}

Microarray data from cells exposed to BC (7 and $9 \mu \mathrm{g} / \mathrm{mL})$ (previously published data set [18]) was used to create gene lists of the 50 genes with lowest false discovery value (FDR) from BC $(7 \mu \mathrm{g} / \mathrm{mL})$, $\mathrm{BC}(9 \mu \mathrm{g} / \mathrm{mL})$ and $\mathrm{BC}(7$ and $9 \mu \mathrm{g} / \mathrm{mL})$. In addition, two new replicate microarray hybridizations were performed (direct comparison between the control and BC $(9 \mu \mathrm{g} / \mathrm{mL})$ ) (method as previously described [18]) identified 19 genes that were either up- or down regulated compared to the control. These new 19 genes were combined with the other 50 genes to generate a new gene list of 69 genes. These genes were present in all the observations (hybridizations) from the previous microarray experiments [18]. These 69 genes were used as responses in a new 50-50 MANOVA analysis of the stress experiment previously described [18] and resulted in 41 genes, showing a statistically significant (FDR < 0.05) difference in expression level between BC $(9 \mu \mathrm{g} / \mathrm{mL})$ and the control (Table 1). This list of significant genes was used to select genes for knock-out analyses and real-time PCR analyses. The $\Delta \Delta \mathrm{C}_{\mathrm{T}}$ calculation (User Bulletin \#2: ABI PRISM 7700 Sequence Detection System) was used to calculate the changes in gene expression compared to the reference genes (accD and gapA) and the

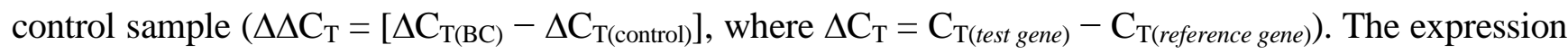
is reported as $\log 2$ of fold change $\left(2^{-\Delta \Delta \mathrm{C}_{\mathrm{T}}}\right)$. For the $\Delta \Delta \mathrm{C}_{\mathrm{T}}$ calculation to be valid, the efficiency of the target amplification and the efficiency of the reference amplification must be approximately equal. This was tested and all primer/probe pairs had an amplification effect higher than $95 \%$. 


\subsection{Pre-Exposure to Osmotic- and Oxidative Stress Experiments}

Cells were exposed to $0.5 \mathrm{M}$ and $0.77 \mathrm{M}$ sodium chloride $(\mathrm{NaCl}): 5 \mathrm{mM}$ and $10 \mathrm{mM}$ salicylic acid (SAL) and $0.1 \mathrm{mM}$ and $0.2 \mathrm{mM}$ methyl viologen (MV) to simulate osmotic- and oxidative stress. The cells were inoculated as described in strains and growth conditions and grown to approx. $1 \times 10^{8} \mathrm{CFU} / \mathrm{mL}$ before being inoculated to fresh medium (containing BC) (1:10 dilution of the inoculation culture). The results are presented as the observed regrowth time in BC.

\subsection{Genome Sequencing (454 (Roche) Sequencing Platform)}

Selection of isolates: Cells exposed to $11.5 \mu \mathrm{g} / \mathrm{mL} \mathrm{BC}$ (resulting in same regrowth time as previously using $9 \mu \mathrm{g} / \mathrm{mL}$ ) were grown to OD 0.5 and dilutions were plated on TSA and incubated overnight at $37{ }^{\circ} \mathrm{C}$. From these plates 94 individual colonies were picked (in addition to 3 colonies from the control grown without $\mathrm{BC}$ and 3 negative controls (medium only)) and transferred to a 100 well-format Bioscreen C (MTX Lab Systems, Inc.) (350 $\mu \mathrm{L}$ TSB total volume) for overnight growth at $37{ }^{\circ} \mathrm{C}$ with shaking. Cultures from this plate were initially diluted 1:10 and used to inoculate TSB without or with BC $(12 \mu \mathrm{g} / \mathrm{mL})$ in 2 new 100 well-format plates for growth and on-line turbidity measurement (10 wells per sample and concentration). Based on the results, glycerol stocks were prepared for a selection of the 94 colonies and stored at $-80^{\circ} \mathrm{C}$. One control sample (Control) and two samples from growth in BC (M95 and M100) were tested again for growth in BC before being selected for genome sequencing. A small amount from the freeze stocks were plated on TSA for overnight growth at $37{ }^{\circ} \mathrm{C}$. One colony from each sample were transferred to $5 \mathrm{~mL}$ TSB and grown at $37{ }^{\circ} \mathrm{C}$ overnight and tested for growth in Bioscreen (5 different BC concentrations 11, 12, 13, 14 and $15 \mu \mathrm{g} / \mathrm{mL}$ (all concentrations were below MIC in Bioscreen using a new batch of $\mathrm{BC}$ )). There were 10 replicate wells per isolate and $\mathrm{BC}$ concentration. DNA was purified from the overnight growth in TSB using the Qiagen Blood and Tissue kit (Qiagen). Briefly, $2 \times 500 \mu \mathrm{L}$ bacteria were centrifuged at $5000 \mathrm{~g}$ for $10 \mathrm{~min}$ at $4{ }^{\circ} \mathrm{C}$. The supernatant was discarded and the pellet was frozen at $-80{ }^{\circ} \mathrm{C}$ for later DNA purification. The manufacture protocol for gram-positive bacteria was used in addition to lysozyme in the pretreatment buffer and an RNase step. The concentration and purity of the DNA was analyzed using NanoDrop ND-1000 spectrophotometer (NanoDrop Technologies, Inc.) in addition to EtBr-stained 1\% agarose gel containing $500 \mathrm{ng}$ of each sample. The DNA was sent to the Norwegian High-Throughput Sequencing Centre (NSC) (University of Oslo) for genome sequencing using the 454 (Roche) sequencing platform.

Data analysis: The sequence reads were assembled and analyzed using the CLC Genomic Workbench software (version 3.7.1; CLC Bio.: Aarhus, Denmark, 2010). The three isolates, Control, M95 and M100, were all assembled against the E. coli U00096 reference genome. The SNP Detection tool (using default parameters) was then used to search for single point mutations.

\section{Conclusions}

There are most likely several interacting mechanisms involved in the response to $\mathrm{BC}$ at concentrations allowing growth, both $\mathrm{BC}$ specific and general stress related, and the apparent inheritance of tolerance to $\mathrm{BC}$ in E. coli. In summary, we have shown that exposure to a BC concentration $25 \%$ below MIC in nutrient medium results in initial killing of $95-99 \%$ of the cells followed by regrowth of a more BC 
tolerant subpopulation of $E$. coli in a sensitive culture and that this tolerance is partly inheritable. To withstand $\mathrm{BC}$ during regrowth, genes responsible for removing $\mathrm{BC}$ from the cytoplasm, the AcrAB-TolC efflux system, and genes involved in maintenance of the outer membrane in response to increased osmotic- and oxidative stress are important. Genome sequencing of a control and two selected isolates showing increased BC-tolerance after growth in concentrations of BC $25 \%$ below MIC identified no common point mutations in the BC tolerant isolates. One point mutation in gene rpsA (Ribosomal protein $\mathrm{S} 1$ ) was observed in one of the isolates. The observed tolerance can therefore not solely be explained by the observed point mutation. Further work is needed to address the mechanisms behind the inheritance of tolerance to $\mathrm{BC}$ and the possible role of the observed single point mutation in gene $\operatorname{rps} A$.

\section{Acknowledgments}

This work was supported by Grant 142656/140 from the Norwegian Research Council and the Found for Research Levy on Agricultural Products.

\section{References}

1. McDonnell, G.; Russell, A.D. Antiseptics and disinfectants: Activity, action, and resistance. Clin. Microbiol. Rev. 1999, 12, 147-179.

2. Gilbert, P.; Moore, L.E. Cationic antiseptics: Diversity of action under a common epithet. J. Appl. Microbiol. 2005, 99, 703-715.

3. Hegstad, K.; Langsrud, S.; Lunestad, B.T.; Scheie, A.A.; Sunde, M.; Yazdankhah, S.P. Does the wide use of quaternary ammonium compounds enhance the selection and spread of antimicrobial resistance and thus threaten our health? Microb. Drug Resist. 2010, 16, 91-104.

4. Langsrud, S.; Sundheim, G.; Borgmann-Strahsen, R. Intrinsic and acquired resistance to quaternary ammonium compounds in food-related Pseudomonas spp. J. Appl. Microbiol. 2003, 95, 874-882.

5. Russell, A.D. Do biocides select for antibiotic resistance? J. Pharm. Pharmacol. 2000, 52, 227-233.

6. Sidhu, M.S.; Heir, E.; Sorum, H.; Holck, A. Genetic linkage between resistance to quaternary ammonium compounds and beta-lactam antibiotics in food-related Staphylococcus spp. Microb. Drug Resist. 2001, 7, 363-371.

7. Braoudaki, M.; Hilton, A.C. Adaptive resistance to biocides in Salmonella enterica and Escherichia coli $\mathrm{O} 157$ and cross-resistance to antimicrobial agents. J. Clin. Microbiol. 2004, 42, 73-78.

8. Braoudaki, M.; Hilton, A.C. Mechanisms of resistance in Salmonella enterica adapted to erythromycin, benzalkonium chloride and triclosan. Int. J. Antimicrob. Agents 2005, 25, 31-37.

9. Langsrud, S.; Sundheim, G.; Holck, A.L. Cross-resistance to antibiotics of Escherichia coli adapted to benzalkonium chloride or exposed to stress-inducers. J. Appl. Microbiol. 2004, 96, 201-208.

10. Sidhu, M.S.; Sorum, H.; Holck, A. Resistance to quaternary ammonium compounds in food-related bacteria. Microb. Drug Resist. 2002, 8, 393-399. 
11. Bore, E.; Hebraud, M.; Chafsey, I.; Chambon, C.; Skjaeret, C.; Moen, B.; Moretro, T.; Langsrud, O.; Rudi, K.; Langsrud, S. Adapted tolerance to benzalkonium chloride in Escherichia coli K-12 studied by transcriptome and proteome analyses. Microbiology 2007, 153, 935-946.

12. Nishino, K.; Yamaguchi, A. Analysis of a complete library of putative drug transporter genes in Escherichia coli. J. Bacteriol. 2001, 183, 5803-5812.

13. Ishikawa, S.; Matsumura, Y.; Yoshizako, F.; Tsuchido, T. Characterization of a cationic surfactant-resistant mutant isolated spontaneously from Escherichia coli. J. Appl. Microbiol. 2002, 92, 261-268.

14. Tattawasart, U.; Maillard, J.Y.; Furr, J.R.; Russell, A.D. Outer membrane changes in Pseudomonas stutzeri resistant to chlorhexidine diacetate and cetylpyridinium chloride. Int. J. Antimicrob. Agents 2000, 16, 233-238.

15. Jones, M.V.; Herd, T.M.; Christie, H.J. Resistance of Pseudomonas aeruginosa to amphoteric and quaternary ammonium biocides. Microbios 1989, 58, 49-61.

16. Sakagami, Y.; Yokoyama, H.; Nishimura, H.; Ose, Y.; Tashima, T. Mechanism of resistance to benzalkonium chloride by Pseudomonas aeruginosa. Appl. Environ. Microbiol. 1989, 55, 2036-2040.

17. Elfalaha, B.M.A.; Russell, A.D.; Furr, J.R. Effect of chlorhexidine diacetate and benzalkonium chloride on the viability of wild-type and envelope mutants of Escherichia coli and Pseudomonas aeruginosa. Lett. Appl. Microbiol. 1985, 1, 21-24.

18. Moen, B.; Oust, A.; Langsrud, S.; Langsrud, O.; Hobman, J.L.; Constantinidou, C.; Kohler, A.; Rudi, K. Global responses of Escherichia coli to adverse conditions determined by microarrays and FT-IR specrtroscopy. Can. J. Microbiol. 2009, 55, 714-728.

19. Deckers, D.; Masschalck, B.; Aertsen, A.; Callewaert, L.; van Tiggelen, C.G.; Atanassova, M.; Michiels, C.W. Periplasmic lysozyme inhibitor contributes to lysozyme resistance in Escherichia coli. Cell Mol. Life Sci. 2004, 61, 1229-1237.

20. Monchois, V.; Abergel, C.; Sturgis, J.; Jeudy, S.; Claverie, J.M. Escherichia coli ykfE ORFan gene encodes a potent inhibitor of C-type lysozyme. J. Biol. Chem. 2001, 276, 18437-18441.

21. Dynes, J.J.; Lawrence, J.R.; Korber, D.R.; Swerhone, G.D.W.; Leppard, G.G.; Hitchcoock, A.P. Morphological and biochemical changes in Pseudomonas fluorescens biofilms induced by sub-lethal exposure to antimicrobial agents. Can. J. Microbiol. 2009, 55, 163-178.

22. Mc Cay, P.H.; Ocampo-Sosa, A.A.; Fleming, G.T. Effect of subinhibitory concentrations of benzalkonium chloride on the competitiveness of Pseudomonas aeruginosa grown in continuous culture. Microbiology 2010, 156, 30-38.

23. During, K.; Porsch, P.; Mahn, A.; Brinkmann, O.; Gieffers, W. The non-enzymatic microbicidal activity of lysozymes. FEBS Lett. 1999, 449, 93-100.

24. Gerken, H.; Misra, R. Genetic evidence for functional interactions between TolC and AcrA proteins of a major antibiotic efflux pump of Escherichia coli. Mol. Microbiol. 2004, 54, 620-631.

25. Ma, D.; Cook, D.N.; Alberti, M.; Pon, N.G.; Nikaido, H.; Hearst, J.E. Genes acrA and acrB encode a stress-induced efflux system of Escherichia coli. Mol. Microbiol. 1995, 16, 45-55.

26. Gajiwala, K.S.; Burley, S.K. HDEA, a periplasmic protein that supports acid resistance in pathogenic enteric bacteria. J. Mol. Biol. 2000, 295, 605-612. 
27. Pomposiello, P.J.; Bennik, M.H.; Demple, B. Genome-wide transcriptional profiling of the Escherichia coli responses to superoxide stress and sodium salicylate. J. Bacteriol. 2001, 183, 3890-3902.

28. Shaw, K.; Miller, N.; Liu, X.; Lerner, D.; Wan, J.; Bittner, A.; Morrow, B. Comparison of the changes in global gene expression of Escherichia coli induced by four bactericidal agents. J. Mol. Microbiol. Biotechnol. 2003, 5, 105-122.

29. Raivio, T.L. Envelope stress responses and Gram-negative bacterial pathogenesis. Mol. Microbiol. 2005, 56, 1119-1128.

30. Skorko-Glonek, J.; Zurawa, D.; Kuczwara, E.; Wozniak, M.; Wypych, Z.; Lipinska, B. The Escherichia coli heat shock protease HtrA participates in defense against oxidative stress. Mol. Gen. Genet. 1999, 262, 342-350.

31. Neidhardt, F.C. Escherichia coli and Salmonella: Cellular and Molecular Biology, 2nd ed.; ASM Press: Washington, DC, USA, 1996.

32. Pratt, L.A.; Hsing, W.; Gibson, K.E.; Silhavy, T.J. From acids to osmZ: Multiple factors influence synthesis of the OmpF and OmpC porins in Escherichia coli. Mol. Microbiol. 1996, 20, 911-917.

33. Jung, J.U.; Gutierrez, C.; Martin, F.; Ardourel, M.; Villarejo, M. Transcription of osmB, a gene encoding an Escherichia coli lipoprotein, is regulated by dual signals. Osmotic stress and stationary phase. J. Biol. Chem. 1990, 265, 10574-10581.

34. Boulanger, A.; Francez-Charlot, A.; Conter, A.; Castanie-Cornet, M.P.; Cam, K.; Gutierrez, C. Multistress regulation in Escherichia coli: Expression of osmB involves two independent promoters responding either to sigmaS or to the RcsCDB His-Asp phosphorelay. J. Bacteriol. 2005, 187, 3282-3286.

35. Storz, G.; Hengge-Aronis, R. Bacterial Stress Responses; ASM Press: Washington, DC, USA, 2000.

36. Loewen, P.C.; Hu, B.; Strutinsky, J.; Sparling, R. Regulation in the rpoS regulon of Escherichia coli. Can. J. Microbiol. 1998, 44, 707-717.

37. Pilsl, H.; Smajs, D.; Braun, V. Characterization of colicin S4 and its receptor, OmpW, a minor protein of the Escherichia coli outer membrane. J. Bacteriol. 1999, 181, 3578-3581.

38. Xu, C.; Wang, S.; Ren, H.; Lin, X.; Wu, L.; Peng, X. Proteomic analysis on the expression of outer membrane proteins of Vibrio alginolyticus at different sodium concentrations. Proteomics 2005, 5, 3142-3152.

39. Bochkareva, E.S.; Girshovich, A.S.; Bibi, E. Identification and characterization of the Escherichia coli stress protein UP12, a putative in vivo substrate of GroEL. Eur. J. Biochem. 2002, 269, 3032-3040.

40. Weber, A.; Jung, K. Profiling early osmostress-dependent gene expression in Escherichia coli using DNA macroarrays. J. Bacteriol. 2002, 184, 5502-5507.

41. Kim, S.Y.; Nishioka, M.; Hayashi, S.; Honda, H.; Kobayashi, T.; Taya, M. The gene yggE functions in restoring physiological defects of Escherichia coli cultivated under oxidative stress conditions. Appl. Environ. Microbiol. 2005, 71, 2762-2765. 
42. Wagner, A.F.; Schultz, S.; Bomke, J.; Pils, T.; Lehmann, W.D.; Knappe, J. YfiD of Escherichia coli and Y06I of bacteriophage T4 as autonomous glycyl radical cofactors reconstituting the catalytic center of oxygen-fragmented pyruvate formate-lyase. Biochem. Biophys. Res. Commun. 2001, 285, 456-462.

43. Tong, S.; Porco, A.; Isturiz, T.; Conway, T. Cloning and molecular genetic characterization of the Escherichia coli gntR, gntK, and gnt $U$ genes of GntI, the main system for gluconate metabolism. J. Bacteriol. 1996, 178, 3260-3269.

44. Lehnen, D.; Blumer, C.; Polen, T.; Wackwitz, B.; Wendisch, V.F.; Unden, G. LrhA as a new transcriptional key regulator of flagella, motility and chemotaxis genes in Escherichia coli. Mol. Microbiol. 2002, 45, 521-532.

45. Gibson, K.E.; Silhavy, T.J. The LysR homolog LrhA promotes RpoS degradation by modulating activity of the response regulator sprE. J. Bacteriol. 1999, 181, 563-571.

46. EcoGene. Available online: http://bmb.med.miami.edu/EcoGene/EcoWeb/ (accessed on 12 Octorber 2005).

47. De Spiegeleer, P.; Sermon, J.; Vanoirbeek, K.; Aertsen, A.; Michiels, C.W. Role of porins in sensitivity of Escherichia coli to antibacterial activity of the lactoperoxidase enzyme system. Appl. Environ. Microbiol. 2005, 71, 3512-3518.

48. E. coli Genome Project. University of Wisconsin, Madison. Available online: http://www.genome.wisc.edu/functional/tnmutagenesis.htm (accessed on 14 January 2005).

49. Nikaido, H.; Zgurskaya, H.I. AcrAB and related multidrug efflux pumps of Escherichia coli. J. Mol. Microbiol. Biotechnol. 2001, 3, 215-218.

50. Detweiler, C.S.; Monack, D.M.; Brodsky, I.E.; Mathew, H.; Falkow, S. virK, somA and $\operatorname{rcsC}$ are important for systemic Salmonella enterica serovar Typhimurium infection and cationic peptide resistance. Mol. Microbiol. 2003, 48, 385-400.

51. Leenanon, B.; Drake, M.A. Acid stress, starvation, and cold stress affect poststress behavior of Escherichia coli O157:H7 and nonpathogenic Escherichia coli. J. Food Prot. 2001, 64, 970-974.

52. Mattison, K.; Kenney, L.J. Phosphorylation alters the interaction of the response regulator OmpR with its sensor kinase EnvZ. J. Biol. Chem. 2002, 277, 11143-11148.

53. Cohen, S.P.; McMurry, L.M.; Hooper, D.C.; Wolfson, J.S.; Levy, S.B. Cross-resistance to fluoroquinolones in multiple-antibiotic-resistant (Mar) Escherichia coli selected by tetracycline or chloramphenicol: Decreased drug accumulation associated with membrane changes in addition to OmpF reduction. Antimicrob. Agents Chemother. 1989, 33, 1318-1325.

54. Harder, K.J.; Nikaido, H.; Matsuhashi, M. Mutants of Escherichia coli that are resistant to certain beta-lactam compounds lack the ompF porin. Antimicrob. Agents Chemother. 1981, 20, 549-552.

55. Thanassi, D.G.; Suh, G.S.; Nikaido, H. Role of outer membrane barrier in efflux-mediated tetracycline resistance of Escherichia coli. J. Bacteriol. 1995, 177, 998-1007.

56. Lambert, P.A.; Hammond, S.M. Potassium fluxes, first indications of membrane damage in micro-organisms. Biochem. Biophys. Res. Commun. 1973, 54, 796-799.

57. Ceccarelli, M.; Danelon, C.; Laio, A.; Parrinello, M. Microscopic mechanism of antibiotics translocation through a porin. Biophys. J. 2004, 87, 58-64. 
58. Goldman, R.A.; Hasan, T.; Hall, C.C.; Strycharz, W.A.; Cooperman, B.S. Photoincorporation of tetracycline into Escherichia coli Ribosomes-Identification of the major proteins photolabeled by native tetracycline and tetracycline photoproducts and implications for the inhibitory-action of tetracycline on protein-synthesis. Biochemistry 1983, 22, 359-368.

59. Agrawal, R.K.; Spahn, C.M.T.; Penczek, P.; Grassucci, R.A.; Nierhaus, K.H.; Frank, J. Visualization of tRNA movements on the Escherichia coli 70S ribosome during the elongation cycle. J. Cell Biol. 2000, 150, 447-459.

60. Spahn, C.M.T.; Blaha, G.; Agrawal, R.K.; Penczek, P.; Grassucci, R.A.; Trieber, C.A.; Connell, S.R.; Taylor, D.E.; Nierhaus, K.H.; Frank, J. Localization of the ribosomal protection protein Tet(O) on the ribosome and the mechanism of tetracycline resistance. Mol. Cell 2001, 7, 1037-1045.

61. Blattner, F.R.; Plunkett, G., Ш; Bloch, C.A.; Perna, N.T.; Burland, V.; Riley, M.; Collado-Vides, J.; Glasner, J.D.; Rode, C.K.; Mayhew, G.F.; et al. The complete genome sequence of Escherichia coli K-12. Science 1997, 277, 1453-1474.

62. RT Color Spot Camera Software. SPOT Imaging Solutions. Available online: http://www.spotimaging.com/software/spot-camera-software-compatibility.html (accessed on 29 September 2004).

63. Spot Advanced Software. SPOT Imaging Solutions. Available online: http://www.spotimaging.com/software/spotadvanced.html (accessed on 29 September 2004).

64. Primer Express Software ABI PRISM ${ }^{\circledR}$ Software. Life Technologies. Available online: https://products.appliedbiosystems.com/ab/en/US/adirect/ab?cmd=catNavigate2\&catID=605537 (accessed on 3 March 2005).

(C) 2012 by the authors; licensee MDPI, Basel, Switzerland. This article is an open access article distributed under the terms and conditions of the Creative Commons Attribution license (http://creativecommons.org/licenses/by/3.0/). 